\title{
THE EFFECTS OF STRYCHNINE AND CAFFEINE UPON THE RATE OF LEARNING
}

\author{
K. S. LASHLEY \\ Department of Psychology of the Johns Hopkins University
}

Among the hypotheses which have been advanced to account for the reintegration of conduction paths in learning three stand out as rather definitely opposed to one another in the neural processes which they imply. The hypothesis suggested by Ladd and Woodworth ('11) assumes inhibition of successive activities as the fundamental process which results in the selection and fixation of random activities. The second hypothesis assumes nervous reinforcement as the fundamental process by which successive acts become linked together in habit-formation. In its vaguest forms this hypothesis refers to pleasure and pain as the reinforcing agents without any attempt to analyze the way in which they act. Its most concrete expression is that given by Angell ('09), though the diagram which he gives has little correspondence with physiological facts. The third hypothesis depends chiefly upon the chance spreading of nervous excitation (Watson, '14 a), or the simultaneous activation of two afferent pathways in such a way that the final common path of one is able to divert the discharge of the other and so bring about a permanent connection between itself and this afferent path (Max Meyer, '11), (Pawlow, '14). If Sherrington's explanation of the spreading of nerve impulses as a result of fatigue of the final common path be accepted, the mechanism implied in this hypothesis is relatively independent of inhibitory and reinforcing activities of the nervous system.

The studies of Verworn and of Sherrington have shown that the primary action of strychnine upon the central nervous system is the reduction of inhibitory processes and their final conversion into processes of excitation. A means is thus pro- 
vided for inducing functional changes in nerve conduction which may have a direct bearing upon the hypotheses mentioned above. It may serve, at least, to distinguish the first, the "inhibition theory," from the others, since, if this theory be true, the reduction of inhibitory processes should retard learning, while the resultant increase in the ease of spread of excitatory processes might be expected to accelerate learning, either by increasing the variety of activities available for selection by repetition (third hypothesis), or by increasing the effects of reinforcing agents such as are presupposed by the second hypothesis. Thus, if strychnine retards learning, it should lend some support to the first hypothesis, if it accelerates it, it will give evidence in favor of the second or third.

The interpretation of the results may be complicated, however, by the locus of attack of the drug. Experimental work has located this definitely only in the intercommunicating cells of the dorsal horn of the spinal cord, but the involvement of the entire body in the convulsions of acute strychnine poisoning indicates a similar reduction of inhibitory processes in the midbrain, or perhaps even in the cerebrum. The reduction of stimulus threshold found by Amantea ('15) after application of strychnine to restricted parts of the cortex also shows an increased excitability of the cortex and probably closely similar action of the drug upon cortical and spinal cells. This evidence seems sufficient to justify the interpretation of any effects of the drug found as due to its general reduction of synaptic resistances.

It was with essentially the above problem in mind that I began a study of the effects of strychnine upon habit-formation. Since caffeine is generally stated to have a physiological action similar to that of strychnine but confined to the cerebrum and since it is so generally used as a stimulant it was included with strychnine in this study of the effects of the central excitants.

The three hypotheses outlined above, while most widely accepted, by no means exhaust the possible explanations of the learning process and the results reported in the following pages have, perhaps, complicated rather than simplified the 
problem. Accumulating evidence of the dependence of the direction of nerve conduction upon the relative refractory phases of the neurons involved (Forbes and Gregg,'15) and the growing acceptance of the all-or-none law of nerve action make it seem less and less probable that any of the current accounts of the neurological basis of habit is in any way adequate to account for the facts. The presentation of the problem in this form has nevertheless seemed of value in spite of the possible falsity of all the hypotheses which it is designed to test, if only as a means of emphasizing the strictly physiological nature of the problem of learning and the necessity for a more concrete formulation of this problem than has hitherto been made.

\section{METHODS IN THE PRESENT EXPERIMENTS}

For testing the effects of the central excitants, albino rats, approximately sixty-five days old, were used. They were trained in the circular graphic maze (Watson, '14 b), time, ? distance, errors, and number of trials required for learning being recorded. The technique of training was essentially that described by Hubbert ('15) with the difference that each animal was given five trials per day and that the training was continued until three successive errorless trials were made during one day's practice.

Administration of drug. The drugs given were strychnine sulphate (Powers and Weightman) and caffeine (pure alkaloid, Merck) in aqueous solution. They were injected subcutaneously in solutions of such strength that $0.10 \mathrm{cc}$. contained the desired dose. The minimum lethal dose of strychnine for an 150 gram rat was determined at the beginning of the experiments as about $0.50 \mathrm{mgm}$. This is usually fatal in about fifteen minutes but its effect varies somewhat with the concentration of the solution and with individual differences in the animals, one rat being killed by $0.10 \mathrm{mgm}$., others surviving $0.50 \mathrm{mgm}$. without convulsions. For study, two concentrations of the drug were used, $0.10 \mathrm{mgm}$. and $0.05 \mathrm{mgm}$. per $0.10 \mathrm{cc}$. of solution. These correspond by weight to doses of about 0.8 and 0.4 
grains, respectively, for a 150 pound man, or sixteen and eight times the maximum therapeutic dose.

The caffeine was administered in doses of $0.50 \mathrm{mgm}$. and 1.00 mgm. These were chosen arbitrarily as corresponding by weight to 4 and 8 grain doses for man. The drugs were administered each day exactly ten minutes before the beginning of training. This time was chosen as the interval after which the first convulsion appears, following the minimum lethal dose of strychnine. Since Goldscheider and Flatau. ('98) have found changes in the cells of the dorsal horn within three minutes after the subcutaneous injection of strychnine the ten minute interval seems ample time to assure the full effect of the drug during training. The absence of any easily recognizable effect of the caffeine made it impossible to note its time of action so the same interval between the administration of the drug and the beginning of training was used with it as with strychnine.

A Luer hypodermic syringe graduated in hundredths cubic centimeters was used for injection. Owing to the small quantity $(0.10 \mathrm{cc}$.) of fluid injected some variation in the size of the dose from day to day was unavoidable. With care, however, it was possible to keep this well within 10 per cent of the total quantity injected. ${ }^{1}$

Method of training. The course of training was as follows. On three consecutive days the rat was confined for fifteen, ten, and.five minutes respectively in the feeding compartment of the maze and was given no food except what was eaten there. On the fourth day training was begun. For the first trial the rat

1 The technique devised for injection has proved so satisfactory that I be- lieve it can be substituted advantageously for that used in many types of work. The usual methods of confining the animals for injection were found to excite them to an extent which threatened to interfere seriously with the experiments and it seemed necessary that the experimenter have both hands free to manipulate the animals. The hypodermic was therefore fastened by a clamp to project over the edge of a table above which was attached a long lever bearing upon the plunger of the syringe and extending below the table-top so that it could be moved by the experimenter's knee. His hands were thus left free to hold the animal without exciting it, and with careful handling, the animals rarely showed any sensitivity to the injection. With practice it is possible to control the quantity of solution injected by this method to within 0.005 cc. 
was pushed out of the starting compartment and the door was closed behind him to avoid the long delay which usually occurs there. In all later trials he was allowed to take his time in starting unless the delay exceeded ten minutes. When he reached the food compartment he was not allowed to retrace the path but was returned to the starting box immediately, getting rarely more than one or two bites of food. After the fifth trial he was confined in the food compartment and allowed to eat for five minutes; then was not fed again until the completion of the next day's practice.

If the rat did not reach the food compartment within one hour after starting he was returned to the home cage, without food, and the trial was continued on the following day. If the food compartment was not reached within less than three hours the animal was discarded. This occurred in the case of only one rat.

Throughout the experiments the animals were fed exclusively on bread and milk and of this only so much as was eaten during the five minutes' confinement in the feeding compartment of the maze. On this diet a few lost weight rapidly but the average loss of all the animals trained was only 5.1 grams, or about 4 per cent of their average weight at the beginning of the experiments. There was no apparent relation between the loss or gain in weight and the drug administered.

Criteria of learning. In computing the results the number of trials preceding the first run without error and also the number preceding three successive errorless runs on the same day have been used as the most dependable criteria of the respective abilities of the groups. ${ }^{2}$

In these experiments and probably in all others where differently treated groups of animals are studied, the rate of running is modified by the differential treatment so that the time consumed in learning, when considered alone, is not reliable as a criterion of the amount of practice. There is no evidence that the distance traversed is similarly influenced and this may be

${ }^{2}$ I have dealt with the irelative reliablity of these two criteria in another paper (Lashley, '17). 
taken as the more trustworthy index to the amount of practice. Since the total distance traversed in learning is greatly influenced by the number of trials, irrespective of whether or not errors are made in all the trials, the total distance traversed during learning is not an accurate index to the number of errors made. The total distance in excess of the direct path through the maze is, on the contrary, closely correlated with the number of errors made, and may perhaps be looked upon as the most accurate measure of error available since we can in no other way evaluate the distances to which the animals penetrate the blind alleys before returning to the direct path.

The relative values of the number of trials and the number of errors made as indices of the effort consumed in learning cannot be determined at present. It is not necessary that a blind alley be entered in order that the alternative entering of the correct path be fixed in the habit. On the other hand it is possible that the failure to obtain food in the blind alley is an important factor in the fixation of the movements required for running over the true pathway. The data on excess distance are given therefore as contributory evidence, the value of which cannot be determined at present. Records were made, also, of the time taken on each trial and of the total distance traversed, thus giving an index of the relative activity of the different groups as determined by their rate of running, and also of the approximate number of errors made by the different rats.

The rôle of chance in determining the results. In every experiment where the course of learning is studied in groups of subjects trained under diverse conditions some control of chance variations in the subject and in the conditions of training is necessary. In very few of the recorded experiments of this type, whether performed on man or animals, have enough subjects been used to make the differences found significantly greater than their probable errors, computed by the usual formulae. Consequently, the results are suggestive rather than conclusive.

The significance of the results based upon few subjects may be increased by a careful control of possible variable factors 
other than those which are intentionally varied in the experimental procedure. Careful selection of the subjects, and rigorous duplication of the experimental conditions may go far towards the elimination of chance variations in the results. The ideal control of small numbers of subjects is to train all at first in exactly the same activity and then with the results of this training as an index of individual variability, to introduce experimental modifications of the training methods in teaching a second activity. But where learning is relatively slow, as in the white rat, where the age of the subjects may be an important item, and where there may be unknown seasonal differences in the rate of learning, the demands upon the time of the experimenter become such that he cannot alone supply all the requisite controls. As I have pointed out in a previous paper (Lashley, '17), such experiments should be either carried out by the cooperation of several experimenters, or the subjects should be trained in the simplest possible tasks so that as many as possible may be trained.

In the present series of experiments the controls employed seem to cover most of the variable factors save that of individual differences in the animals. They were, briefly, the following:

(1) Genotype. The animals trained were all taken from large litters, one animal from each litter being assigned to each of the differentially treated groups. (2) Sex. The animals chosen from any given litter were all of the same sex so that each animal in any group was controlled by a sibling of the same sex in each of the other groups. (3) Age. Except in the second experiment, all animals were beween sixty-five and seventy days of age at the beginning of training. In the second experiment they ranged from seventy-five to eighty-five days. Training was begun with all members of the same litter on the same day. (4) Daily variations. For convenience in injecting the drugs all members of each group were trained at about the same time of day, morning, afternoon, or night, but on successive days the order in which the different groups were taken up was varied so that there was no constant difference in the time 
of day during which the different groups were trained. Hubbert has shown, further, that the rate of learning is not influenced by the time of training. (5) Seasonal variations. No seasonal variation in the learning ability of the rat has been demonstrated, but to control possible variations the experiments were condensed into the shortest possible time and corresponding members of all groups were trained at the same time.

Differences of weight. Where differences in the weight of siblings existed their distribution to the different groups was left to chance. The actual differences in the average weights of the groups were very slight.

Individual differences in the rats other than those noted above were beyond control and may have played some part in determining the results obtained. A further argument, however, in favor of the validity of the differences found between the different groups as indices of the effects of the drugs is the internal agreement between the results of the different experiments which will be considered later.

In the training of animals the personal equation of the experimenter may be influential in deciding the rate of learning. I have sometimes thought that my methods of handling the animals influenced their behavior in the maze, but I have not been able to get any definite evidence of such an influence. Throughout the experiments I made every effort to keep the treatment of all the animals the same and to detect any involuntary favoring of one group or another. Furthermore, the most significant check upon the personal equation is the fact that the results obtained were wholly unexpected and by no means agreeable to my preconceived notion of the probable effects of the drugs.

THE EFFECT OF THE DRUGS UPON THE GENERAL ACTIVITY OF THE RATS

It, is generally stated that large doses of strychnine increase the activity of animals, making them restless and increasing the extent of their reactions to stimuli. I have not found any 
concentration of strychnine which notably increases the general activity of the rat. After the minimum lethal dose the animals crouch on the floor of the cage and remain unusually quiet, unless stimulated, until the onset of convulsions. At the same time the irritability to auditory stimuli is very much increased, and the slightest noise will make them leap high in the air.

The dose of $0.10 \mathrm{mgm}$., like the lethal dose, seems to reduce spontaneous activity and to lower the threshold to auditory stimuli. $^{3}$ After five to ten minutes a coarse tremor, which may be so marked as to resemble a scratching reflex, is visible when the rat raises one foot from the floor. At the same time a marked incoordination of movement appears. The animals are unable to leap accurately or to prevent themselves from falling from the experimenter's hands, and in walking their feet are set down heavily so that the sound may be heard at some distance. When they are frightened their movements become badly incoördinated and even convulsive.

The computation of the rate of running in the maze shows that they move slowly. Besides this they frequently show a characteristic slowing of movement and hesitation when approaching the turns in the maze, so that their progress is a series of quick dashes, alternating with pauses ten seconds or more in length at the turnings of the maze. This behavior may be present even when errors are no longer made.

This description applies to the majority of the animals in group A, experiment 1 (table 1). The animals in the second experiment (group E) rarely showed any such activities, and my notes on them reiterate from day to day "no perceptible effect of the drug." Tremor was sometimes noted but only two of the sixteen showed hesitation at the turns of the maze. The animals used in the second experiment were bred during the winter and were older and much larger than those used in the first experiment. Since in the two experiments the dose was not regulated to the weight of the animals it is almost certain that it was relatively smaller for the group $\mathrm{E}$ than for

${ }^{3}$ Probably the excitability to other strmul is also increased, but this is more difficult to determine. 
the group A and that the physiological effects were, on this account, less.

The dose of $0.05 \mathrm{mgm}$. had a much less pronounced effect on the animals than the larger one. Except for an occasional tremor they seemed in no wise different from those which had not received the drug.

Effects of the caffeine, in any quantity, were difficult to detect. In general, its administration seemed to be followed by some increase in timidity, exbibited in attempts to escape from the experimenter's hands, to run out of the food compartment of the maze at the experimeter's approach, and to hide in the corners of the maze. This did not seem to be present after the second or third day's practice. No tremor or inaccuracy of movement was noted after injection of caffeine.

There is some, though not very certain evidence of the establishment of tolerance to the drugs. After daily injections for two weeks no symptoms were noted in any of the animals following injections of 0.10 or even larger doses of strychnine, and the animals receiving caffeine seemed normal in behavior.

There were no deleterious after effects from the use of the drugs. In some cases $0.10 \mathrm{mgm}$. of strychnine was given daily for three months. At the end of this time the animals were well nourished and healthy. Practically all were mated, later, and produced large healthy litters.

THE INFLUENCE OF THE DRUGS UPON THE AMOUNT OF PRACTICE REQUIRED FOR LEARNING

Program of experiments. A preliminary experiment was carried out upon four groups of animals receiving respectively $0.10 \mathrm{mgm}$. of strychnine, $0.05 \mathrm{mgm}$. of strychnine, $0.50 \mathrm{mgm}$. of caffeine, and $0.10 \mathrm{cc}$. of distilled water. The animals were trained until a record of three successive errorless runs was reached, were then kept without practice for four weeks, and were finally retrained without the drugs to test the retention of the habit. When they were again able to thread the maze without error, their speed and accuracy under the influence 
of the different drugs was tested. The experiment gave fairly clear results for the larger doses of strychnine and caffeine, but as a test of its validity two other experiments, one with strychnine and one with caffeine, were carried out. The program of the different experiments, with the number of animals trained, is given in table 1.

TABLE 1

Synopsis of experiments. Data are given separately on three experiments in each of which the animals were trained simultaneously, with control of age, sex, genotype, etc.

\begin{tabular}{c|c|c|c}
\hline oroup & Drug & Numaga OF Rats & Aar IN Dars \\
\hline Experiment & 1. June-September, 1915. Learning; re-learning, and efficiency \\
\multicolumn{3}{c}{ tested } \\
\hline A & Strychnine, 0.10 mgm. & 10 & $60-70$ \\
B & Strychnine, 0.05 mgm. & 9 & $60-70$ \\
C & Caffeine, 0.50 mgm. & 9 & $60-70$ \\
D & Water, 0 10 cc. & 10 & $60-70$ \\
\hline
\end{tabular}

Experiment 2. October-December, 1915. Learning tested

\begin{tabular}{l|l|l|l}
\hline E & $\begin{array}{l}\text { Strychnine, 0.10 mgm. } \\
\text { W }\end{array}$ & $\begin{array}{l}16 \\
16\end{array}$ & $\begin{array}{l}70-90 \\
70-90\end{array}$ \\
\hline \multicolumn{2}{c|}{ Experiment 3. February-April, 1916. } & Learning tested \\
\hline G & Caffeine, 0.50 mgm. & 6 & $60-70$ \\
H & Caffeine, 1.00 mgm. & 6 & $60-70$ \\
I & Water, 0 10 cc. & 6 & $60-70$ \\
J & Strychnine, 0.10 mgm. & & $60-70$ \\
\hline
\end{tabular}

The effects of strychnine on learning. Three groups of animals, A, B, and E, were trained after injection of strychnine and control groups, D and F, receiving only water, were trained at the same time. The number of trials required by each of the animals in these five groups for reaching the standard of three successive errorless runs is shown in figure 1 . The average numbers of trials required for the five groups to meet the two criteria of learning are given in table 2.

Groups A, B, and D were trained at the same time and under the same conditions. Among them it appears that the group 
receiving the smaller dose of strychnine is not significantly different from that receiving water only. Judged by the standard of the first errorless run it is superior, by that of three errorless runs it is inferior. In neither case is the difference enough greater than its probable error to be significant; there is no indication that the strychnine had any effect upon

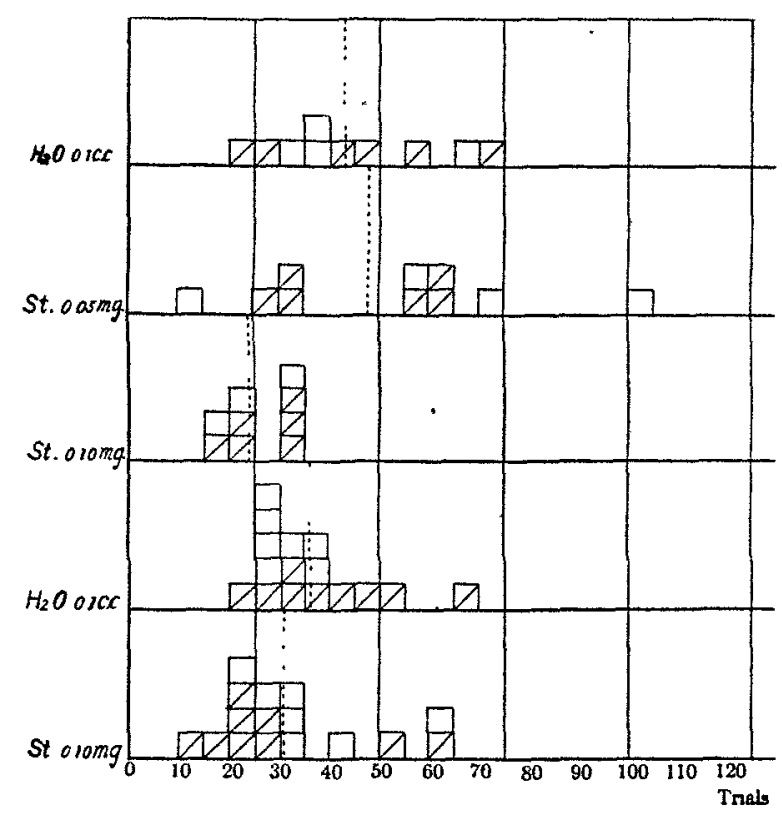

FIG. 1. A comparison of the number of trials required for learning by animals trained after injection of strychnine and normal animals (receiving injections of water only). The squares represent each one animal; the diagonal lines indicate females. For each group the number of animals making each score is shown on the ordinates, the number of trials required for learning on the abscissae. The dotted lines show the averages of the groups.

the learning of this group. The heavier dose of strychnine, on the contrary, seems to have reduced the number of trials required for learning. A comparison of group A with the control group D shows, as a probable result of the administration of the strychnine, a reduction of 36 to 44 per cent in the number of trials required to meet the two criteria of learning. Both 
differences are at least three times their probable errors and therefore almost certainly the result of the differential treatment of the two groups. In the second strychnine experiment (groups $\mathrm{E}$ and $\mathrm{F}$ ) the superiority of the drugged over the normal animals is less pronounced, amounting to only 18 per cent for the first errorless run and 11 per cent for three successive errorless runs. The differences also are not significantly greater

TABLE 2

A comparison of the number of trials required for learning by rats after injections of strychnine and of water

\begin{tabular}{|c|c|c|c|c|c|}
\hline GROUP & DRUG & \begin{tabular}{|c|} 
NOMBER OF \\
TRIALS PRE- \\
CEDING FIRT \\
WITHOOT ERROR
\end{tabular} & $\begin{array}{l}\text { PER CENT } \\
\text { OF WATER } \\
\text { CONTROL }\end{array}$ & $\begin{array}{c}\text { NUADBE OF } \\
\text { TRIALS PHE- } \\
\text { CEDING TH RLE } \\
\text { BUCOEBSIVE } \\
\text { W1THOUT ERHOR }\end{array}$ & $\begin{array}{l}\text { PER CENT } \\
\text { OF WATER } \\
\text { CONTROL }\end{array}$ \\
\hline $\mathrm{D}$ & Water, $010 \mathrm{cc}$. & $230 \pm 24$ & 1000 & $435 \pm 38$ & 1000 \\
\hline A & Strychnine, $0.10 \mathrm{mgm}$. & $14.8=12$ & 643 & $245 \pm 14$ & 563 \\
\hline B & Strychnine, $005 \mathrm{mgm}$. & $204=23$ & 887 & $486 \pm 54$ & 1117 \\
\hline F & Water, $010 \mathrm{cc}$ & $196 \pm 15$ & 1000 & $351 \pm 18^{*}$ & 1000 \\
\hline $\mathbf{E}$ & Strychnine, $0.10 \mathrm{mgm}$. & $161 \pm 17$ & 821 & $310 \pm 24$ & 883 \\
\hline
\end{tabular}

\begin{tabular}{|c|c|c|}
\hline \multicolumn{3}{|c|}{ Differences } \\
\hline $\begin{array}{l}D-A \\
D-B \\
F-E\end{array}$ & $\begin{array}{l}82 \pm 27 \\
26 \pm 34 \\
35 \pm 22\end{array}$ & $\begin{array}{rl}19 & 0 \pm 41 \\
51 & 1 \pm 6 \\
41 & \pm 30\end{array}$ \\
\hline
\end{tabular}

* In a previous discussion of these data (Lashley, '17) a mistake was made in computing the probable error of this average. The error was large but does not significantly affect the conclusions of that paper.

than their probable errors, so that from these data alone the second experiment lends little support to the first.

As has been brought out in the earlier discussion, however, the drugged animals in this experiment showed in other respects a lesser effect of the drug than did those used in the first experiment. The records of the behavior of the animals of group $\mathrm{E}$ in the maze give only two rats which showed tremor after injection of strychnine and these two animals required fewer trials for learning than any others in the group. It is 
probable, then, that when the greater weight and age of the animals used in this experiment is taken into account, the group corresponds rather to group B of the first experiment, which also showed no tremor resulting from the drug and no superiority over the controls.

The number of trials as a measure of the amount of practice resulting in a given degree of efficiency is probably less dependable than the number of errors made during practice. The distance traversed during training in excess of the shortest path through the maze expresses the amount of practice fairly accurately and the average excess distance has been computed

TABLE 3

A comparison of the distance traversed in excess of the true pathway during learning of the maze by rats after injections of strychnine sulphate and of water

\begin{tabular}{|c|c|c|c|}
\hline GROUP & DREG & EXCESB DIETANCE & $\begin{array}{c}\text { PER CENT OF } \\
\text { WATER CONTROL }\end{array}$ \\
\hline $\begin{array}{l}D \\
A \\
A\end{array}$ & $\begin{array}{l}\text { Water, } 0.10 \mathrm{cc} . \\
\text { Strychnine, } 010 \mathrm{mgm} \text {. } \\
\text { Strychnine, } 0.05 \mathrm{mgm} \text {. }\end{array}$ & $\begin{array}{l}\text { meters } \\
266.8 \\
1598 \\
265.7\end{array}$ & $\begin{array}{r}1000 \\
59.8 \\
996\end{array}$ \\
\hline $\begin{array}{l}\mathrm{F} \\
\mathrm{C}\end{array}$ & $\begin{array}{l}\text { Water, } 010 \text { cc. } \\
\text { Strychnine, } 0.10 \mathrm{mgm} .\end{array}$ & $\begin{array}{l}2118 \\
146.1\end{array}$ & $\begin{array}{r}100.0 \\
68.9\end{array}$ \\
\hline
\end{tabular}

for each of the groups trained. These averages are given in table 3 , and the individual records in figure 2 . In the first experiment there is practically no difference between the group receiving $0.05 \mathrm{mgm}$. of strychnine and the control group. In both experiments the groups receiving the larger dose of strychnine, $0.10 \mathrm{mgm}$., traversed a shorter distance in excess of the true pathway than did the control groups. In the first experiment this saving amounted to 41.2 per cent and in the second experiment to 31.1 per cent. This difference between the groups in the second experiment is greater than that revealed by the number of trials. It is probable that the excess distance, or number of errors represents more accurately than the 
number of trials the actual amount of practice required for the attainment of a given degree of proficiency and, hence, that the results of the first and second experiments are more nearly in accord than could be determined from the data on the number of trials alone.

The results may be judged in yet another way and one which gives a still more reliable basis for comparison than the average

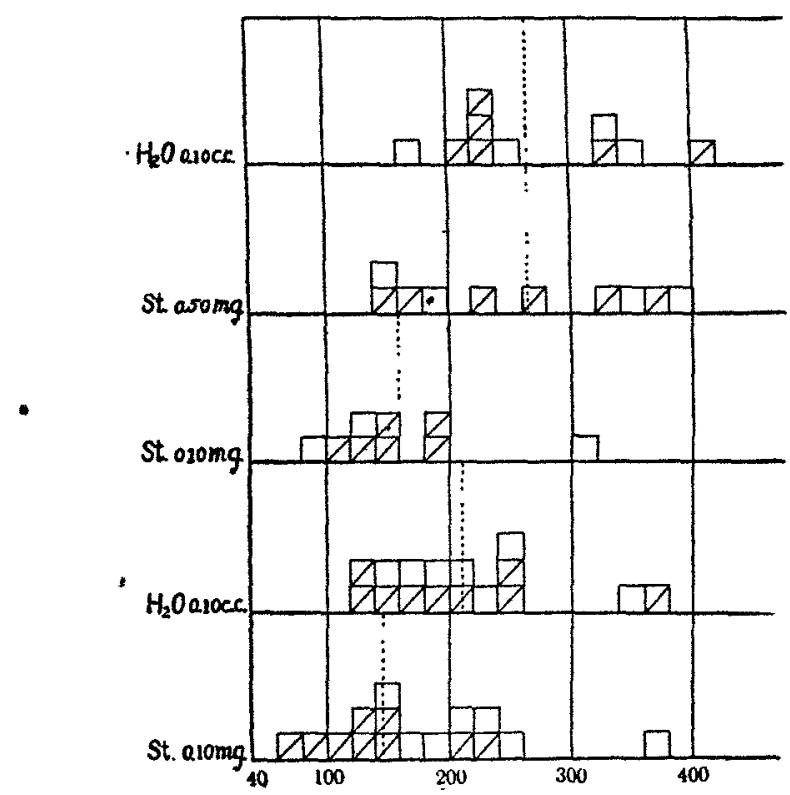

FIG. 2. A comparison of the total excess distance over the shortest path through the maze traversed during training by rats under the influence of strychnine and by normal animals. Arranged as figure 1, except that the abscissae represent meters.

number of trials required for learning. The method by which the animals were selected for training makes it possible to compare each animal with a sibling of the same sex trained under identical conditions. Täble 4 gives the results of such a comparison of the rats with their individual controls. Of the animals which received $0.05 \mathrm{mgm}$. of strychnine 60 per cent were superior to their controls. Eighteen out of 25, or 72 per cent 
of those receiving the larger dose of strychnine were superior to their controls. This comparison of individuals eliminates the excess weight given to extreme variates by the computation of averages and forms a basis for an estimation of the regularity of action of the drug. The results are consistent with those obtained from the averages of trials and distances and lend additional support to the view that the superiority of groups $A$ and $E$ over their controls is the result of the action of the drug and not merely a chance variation.

The evidence from various sources, when massed together, seems dependable. The animals receiving the smaller dose of strychnine were not affected by the drug. The larger animals showed little effects of the drug either upon their general tonic

TABLE 4

The proportion of rats receiving strychnine which learned the maze in fewer trials than their individual controls

\begin{tabular}{|c|c|c|c|c|}
\hline GROUP & DRUG & $\begin{array}{l}\text { NUMBER LEARN- } \\
\text { TNG IN FEWER } \\
\text { TRIALE THAN } \\
\text { THEIR CONTROLS }\end{array}$ & \begin{tabular}{|} 
NOMBER LEARN- \\
ING IN MORE \\
TRIALS THAN \\
THEIR CONTROLS
\end{tabular} & $\begin{array}{l}\text { PER CENT } \\
\text { BUPERIOR TO } \\
\text { CONTROLS }\end{array}$ \\
\hline B & Strychnine, $005 \mathrm{mgm}$. & 6 & 4 & 60 \\
\hline A & Strychnine, $010 \mathrm{mgm}$. & 8 & 1 & 88 \\
\hline $\mathrm{E}$ & Strychnine, $010 \mathrm{mgm}$. & 10 & 6 & 62 \\
\hline
\end{tabular}

condition or their rate of learning, with the exception of two which showed tremor and learned more rapidly than the other members of the group. The smaller rats, after the large dose of strychnine, showed a fine tremor and learned the maze in considerably less time than was required by the controls. The evidence points to an acceleration of learning resulting from the administration of strychnine, but only when it is given in doses large enough to produce observable alterations in muscular tonus.

Time of action of the drug. To test whether the acceleration is due to the immediate effects of the drug or to a general alteration in metabolism another series of rats was trained in which the strychnine was administered daily five minutes after training instead of before. The results of this test are given in table 
5. Apparently the strychnine so given had a retarding effect upon learning, but while the difference between the strychninized animals and their controls is fairly great, the number of animals is so small that no dependence can be placed upon the difference. In this case the dose was graduated to the weight of the animals, $0.10 \mathrm{mgm}$. of strychnine to each hundred grams weight of the animal so that the immediate effects of the drug resembled those found in the first experiment. The test suggests that the acceleration of learning found for groups $A$ and $E$ is the result of the immediate action of the drug.

The influence of caffeine on the rate of learning. The tests of the effects of caffeine were made in the same way as those with strychnine. Three groups of rats were trained after doses

TABLE 5

A comparison of the number of trials required for learning by rats after injection of water before training, and of $0.10 \mathrm{mgm}$. of strychnine after each day's practice

\begin{tabular}{|c|c|c|c|c|c|}
\hline GROUP & DRUG & $\begin{array}{l}\text { NOMBER OF } \\
\text { TRIALS PRECED- } \\
\text { ING FIRST } \\
\text { ERRORL ESE KUN }\end{array}$ & $\begin{array}{l}\text { PER CENT } \\
\text { OF WATER } \\
\text { CONTROL }\end{array}$ & $\begin{array}{l}\text { NUMBER OF } \\
\text { TBINLS PRECED- } \\
\text { ING THREE } \\
\text { SUCCEBSIVE } \\
\text { WITHOUT ERROR }\end{array}$ & $\begin{array}{l}\text { PER CENT } \\
\text { OF WA TEK } \\
\text { CONTROL }\end{array}$ \\
\hline I & Water, $0.10 \mathrm{cc}$. & $143=2.2$ & 1000 & $300 \neq 28$ & 1000 \\
\hline $\mathrm{J}$ & Strychnine, $010 \mathrm{mgm}$. & $180=14$ & 1258 & $425 \pm 42$ & 1416 \\
\hline
\end{tabular}

of $0.50 \mathrm{mgm}$. and $1.00 \mathrm{mgm}$. of the drug and others receiving only water were trained at the same time. The average numbers of trials required for learning, as estimated from the first errorless run and from three successive errorless runs, are given in table 6 . In groups $\mathrm{G}$ and $\mathrm{H}$ the dose was regulated to the weight of the different animals on the basis of the above doses for an hundred gram rat, so that these groups received relatively more of the drug than did group $\mathrm{C}$.

In every case the rats receiving caffeine required a greater number of trials for learning than did their water controls. The differences are quite large, from one and one half to three times as many trials being required by the caffeinized animals as by normal ones. The differences between the groups are at least three times their probable errors and hence significant. 
The drug seemed to affect all the animals that received it in the same way. Of the 21 animals trained after injection of caffeine only one required as few trials for learning as did his individual control. The results of the comparison of individual records are given in table 8 . Further, no animal that was given caffeine learned in fewer trials than the average of the control animals, as appears from figure 3.

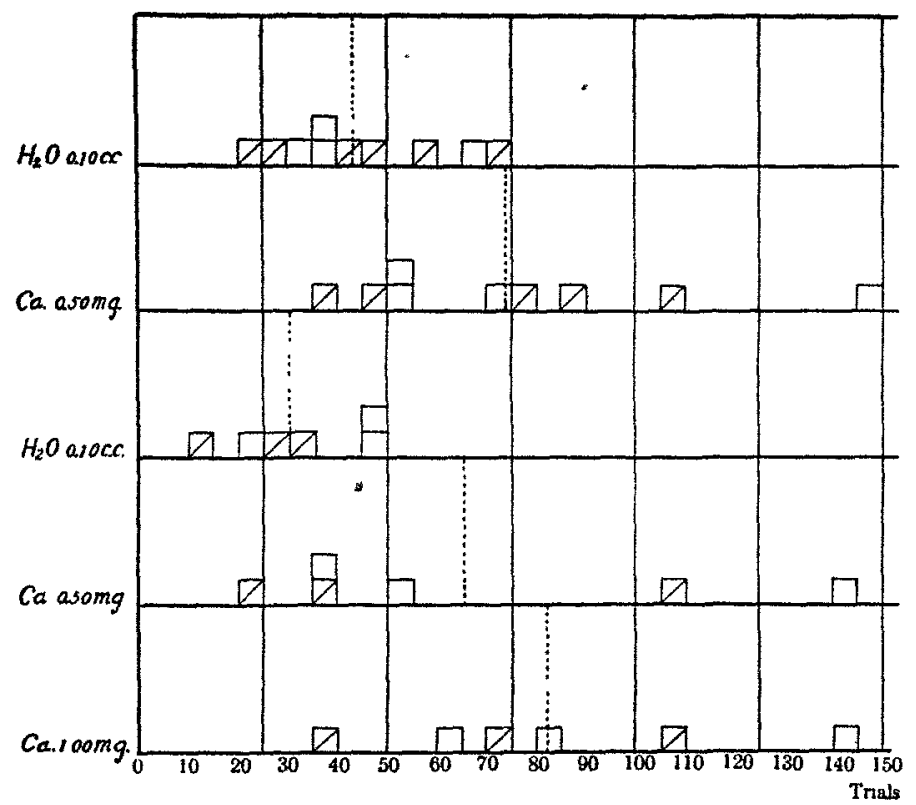

Fig. 3. A comparison of the number of trials required for learning by animals trained after injection of caffeine with that required by normal ones. Arranged as figure 1 .

The distance traversed in excess of the true pathway, or approximately, the number of errors made, also shows the caffeinized animals inferior to the controls. The individual records of excess distance are given in figure 4 and the averages in table 7.: The proportions are somewhat less than those given by the data on the number of trials but are still too large to be explicable as the result of chance. 
TABLE 6

$A$ comparison of the number of trials required for learning by rats after injections of caffeine and of water

\begin{tabular}{|c|c|c|c|c|c|}
\hline GROUP & DREG & $\begin{array}{c}\text { NCARB ER OF } \\
\text { TRAAIA PRECRD- } \\
\text { ING FTRST } \\
\text { WITHOUT ERROR }\end{array}$ & $\begin{array}{l}\text { PER CENT } \\
\text { OF WATER } \\
\text { OONTROL }\end{array}$ & $\begin{array}{l}\text { NOMBER OF } \\
\text { TRALA PRECED- } \\
\text { TNG THREE ERR- } \\
\text { RORLESS HUNB }\end{array}$ & $\begin{array}{l}\text { FER CENT } \\
\text { OF WATER } \\
\text { CONTROI }\end{array}$ \\
\hline $\begin{array}{l}\mathrm{D} \\
\mathrm{C}\end{array}$ & $\begin{array}{l}\text { Water, } 0.10 \text { ce. } \\
\text { Caffeine, } 050 \mathrm{mgm} .\end{array}$ & $\begin{array}{ll}23 & 0 \pm 24 \\
32 & 4 \pm 3.0\end{array}$ & $\begin{array}{l}1000 \\
1408\end{array}$ & $\begin{array}{l}435 \pm 3.8 \\
744 \neq 75\end{array}$ & $\begin{array}{l}100.0 \\
171.0\end{array}$ \\
\hline I & Water, $0.10 \mathrm{cc}$ & $143 \pm 2.2$ & 1000 & $30.0 \pm 28$ & 100.0 \\
\hline G & Caffeine, 0.50 & $31.3 \pm 6.3$ & 218.8 & $653 \neq 120$ & 217.6 \\
\hline H & Gaffeine, $1.00 \mathrm{mgm}$. & $430 \pm 5.1$ & 3007 & $826 \pm 92$ & 2753 \\
\hline \multicolumn{6}{|c|}{ Differences } \\
\hline $\mathrm{C}-\mathrm{D}$ & & $9.4 \pm 3.8$ & & $30.9 \pm 7.8$ & \\
\hline G-I & & $17.0 \pm 2.9$ & & $35.3 \pm 123$ & \\
\hline H-I & & $28.7 \pm 5.6$ & & $52.6 \pm 96$ & \\
\hline
\end{tabular}

TABLE 7

Distance in excess of true pathway traversed by rats after injections of caffeine and of water

\begin{tabular}{|c|c|c|c|}
\hline anotP & Dose & EXCERS DIBTANCE & $\begin{array}{c}\text { PER CENT OP } \\
\text { WATER CONTROL }\end{array}$ \\
\hline $\begin{array}{l}\text { D } \\
\text { C }\end{array}$ & $\begin{array}{l}\text { Water, } 0.10 \mathrm{cc} . \\
\text { Caffeine, } 050 \mathrm{mgm} \text {. }\end{array}$ & $\begin{array}{l}\text { meters } \\
266.8 \\
436.1\end{array}$ & $\begin{array}{l}1000 \\
1638\end{array}$ \\
\hline $\begin{array}{l}\mathrm{I} \\
\mathrm{G} \\
\mathrm{H}\end{array}$ & $\begin{array}{l}\text { Water, } 0.10 \mathrm{cc} \text {. } \\
\text { Caffeine, } 0.50 \mathrm{mgm} \text {. } \\
\text { Caffeine, } 1.00 \mathrm{mgm} \text {. }\end{array}$ & $\begin{array}{l}2059 \\
373.7 \\
4559\end{array}$ & $\begin{array}{l}100.9 \\
181.5 \\
2214\end{array}$ \\
\hline
\end{tabular}

TABLE 8

The proportion of rats receiving caffeine which required a greater number of trials for learning the maze than did their individual controls

\begin{tabular}{|c|c|c|c|c|}
\hline GROUP & DRUG & \begin{tabular}{|} 
NOMBERR LEARN- \\
ING IN ITEWER \\
TRIALS THAN \\
CONTROLS
\end{tabular} & $\begin{array}{l}\text { NOMBER LEARN- } \\
\text { ING IN MORE } \\
\text { TRLALA TRAN } \\
\text { CONTROLS }\end{array}$ & $\begin{array}{l}\text { PER CEATT INFE- } \\
\text { RTOR TO CONTHOLS }\end{array}$ \\
\hline $\begin{array}{l}\mathrm{C} \\
\mathrm{G} \\
\mathrm{H}\end{array}$ & $\begin{array}{l}\text { Caffeine, } 0.50 \mathrm{mgm} \text {. } \\
\text { Caffeine, } 0.50 \mathrm{mgm} \text {. } \\
\text { Caffeine, } 1.00 \mathrm{mgm} \text {. }\end{array}$ & $\begin{array}{l}0 \\
1 \\
0\end{array}$ & $\begin{array}{l}9 \\
5 \\
6\end{array}$ & $\begin{array}{r}100 \\
83 \\
100\end{array}$ \\
\hline
\end{tabular}


As in the case of the tests on strychnine, the number of animals trained is small, but the differences brought out are so pronounced in every case that we seem justified in concluding $\checkmark$ definitely that caffeine has a retarding effect upon the rate of learning the maze.

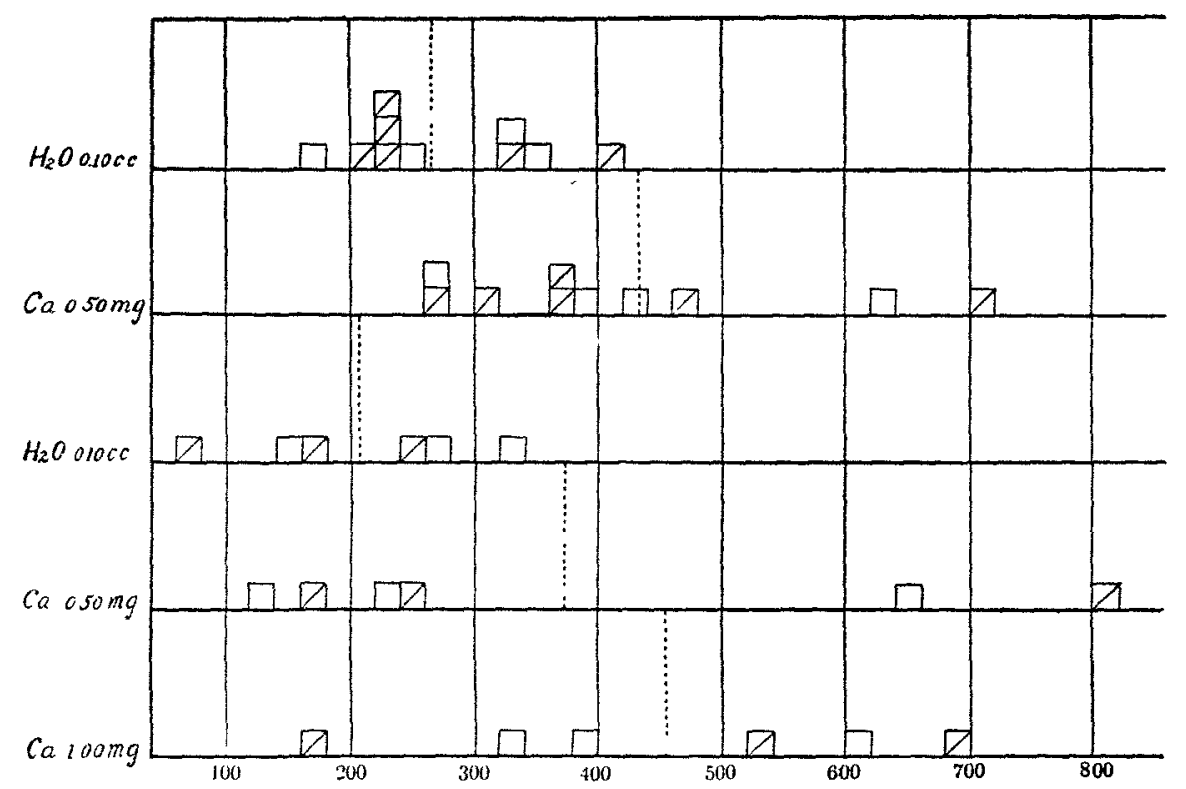

Frg. 4. A comparison of the total excess distance over the shortest path through the maze traversed by animals under the influence of caffeine and by normal animals. Arranged as figure 2.

\section{THE EFFECT OF THE DRUGS UPON RETENTION}

When each animal in experiment 1 had made a perfect record it was kept without further training for twenty days and was then tested for retention without further administration of the drugs. The criterion used in testing relearning was the same as that for learning: three successive trials without error. The average numbers of trials required by the different groups to reach this standard are given in table 9 . The range of variation in each group was very great, from 1 to 30 or more trials 
and the differences apparent in the table are, perhaps, not great enough to be significant. Seemingly, the rats which learned most quickly and consequently received the smallest amount of practice, required the most practice for re-acquirement of the habit, but the great variability within the groups makes such a conclusion doubtful.

EFFECTS OF THE DRUGS UPON THE RATE OF MOVEMENT IN THE

MAZE

While the results seem precise enough to demonstrate an accelerating effect for strychnine and a retarding effect for caffeine upon the rate of learning it is by no means clear how these effects are brought about or whether they actually bear

TABLE 9

The average number of trials required for relearning by the rats in experiment 1

\begin{tabular}{|c|c|c|c|}
\hline GRŐ́ & DRUG & $\begin{array}{l}\text { AVERAGE NTIMBER OF } \\
\text { TRIALS REQUIRED } \\
\text { FOR LEARNINA }\end{array}$ & $\begin{array}{l}\text { AVERAGE NUSBER OF } \\
\text { THIALS REQVIRED } \\
\text { FOR RELEA ILNING }\end{array}$ \\
\hline$A$ & Strychnine, $010 \mathrm{mgm}$. & 245 & 18.8 \\
\hline B & Strychnine, $005 \mathrm{mgm}$. & 486 & 129 \\
\hline $\mathrm{C}$ & Caffeine, $050 \mathrm{mgm}$. & 744 & 121 \\
\hline D & Water, $010 \mathrm{cc}$ & 435 & 9.9 \\
\hline
\end{tabular}

upon the theories previously outlined. The maze habit is so complex and demands the formation of so many new functional conduction paths that failure or success in learning may be only indirectly or not at all the result of changes in the rate of formation of such pathways. Some indication of the mode of action of the drugs is given by the behavior of the animals in approaching the turns of the maze and by the data obtained upon the relative time required by the different groups and the rate of running at different stages of the learning process. The tracings of the paths followed by the animals in learning the maze have been measured and the average time, distance, and rate of running of the different groups have been computed. The results are summarized in table 10. The rate, determined by dividing the distance by the time, is subject to error from 
the fact that no allowance could be made for the times during which the rats were inactive. In the earlier trials many of the animals remain quiet in the corners of the maze for rather long periods, so that the differences in rate recorded for the first trials represent differences in the amount of time spent in inactivity rather than differences in actual rate of running during activity. The periods of inactivity rarely, if ever, persist after the third trial, however, so that the averages for later trials express more nearly the true rate of movement.

\section{TABLE 10}

The rate at which the animals ran in the maze at different periods during the learning process. The rate is expressed in centimeters per second. Average rales, for the first trial, the three successive errorless trials, and for the intervening trials, are given

\begin{tabular}{|c|c|c|c|c|}
\hline \multirow{2}{*}{ GROUP } & \multirow{2}{*}{ DRUG } & \multicolumn{3}{|c|}{ AVERAGE RATE OF RUNNING } \\
\hline & & First trial & $\begin{array}{c}\text { Three perfect } \\
\text { trials }\end{array}$ & All others \\
\hline A & Strychnine, $0.10 \mathrm{mgm}$. & 22 & 13.4 & 6.5 \\
\hline B & Strychnine, $005 \mathrm{mgm}$. & 29 & 187 & 112 \\
\hline $\mathbf{C}$ & Caffeine, $0.50 \mathrm{mgm}$. & 4.3 & 167 & 14.6 \\
\hline $\mathrm{D}$ & Water, $010 \mathrm{cc}$ & 4.4 & 20.3 & 11.8 \\
\hline$E$ & Strychnine, $010 \mathrm{mgm}$. & 51 & 11.7 & 150 \\
\hline$F$ & Water, $0.10 \mathrm{cc}$ & 77 & 157 & 21.5 \\
\hline $\mathrm{G}$ & Caffeine, $050 \mathrm{mgm}$. & 35 & 18.9 & 171 \\
\hline H & Caffeine, $100 \mathrm{mgm}$. & 71 & 17.9 & 233 \\
\hline$I$ & Water, $010 \mathrm{cc}$ & 36 & 11.3 & 85 \\
\hline \multirow{2}{*}{$\mathbf{J}$} & Strychnine, $0.10 \mathrm{mgm}$. & 49 & & 110 \\
\hline & (after training) & $\begin{array}{ll}49 \\
y\end{array}$ & 12.5 & 119 \\
\hline
\end{tabular}

The table shows that both in the first trial and in the total of all succeeding trials including the three successive errorless ones the strychninized animals ran more slowly than their controls, that those which had received $0.5 \mathrm{mgm}$. of caffeine more closely approximated their controls than did any of the other groups, and that those which received a full milligram of caffeine ran most rapidly. It was impossible to keep accurate records of the amount of time spent by the animals in inactivity, but the longer periods were noted, and in so far as can be determined from these the strychninized rats were more continuously and the 
caffeinized rats less continuously active than their controls, although the differences were not great: This is the inverse relation to the rates of running found and emphasizes the fact which appears most clearly in the averages of all trials, that the movements of the strychninized rats were retarded and those of the caffeinized rats were accelerated by the drugs.

When the averages of all trials, exclusive of the first one and the last three (table 10, last column) are considered the slow movements of the strychnine rats and the rapid movements of the caffeine appear unmistakably. If the records of the rate of running of the water-controls are taken as standard, the average rates of the strychninized animals are (B) 95 , (A) 53 , and (C) 72 per cent of this respectively; those of the caffeinized are (C) 123, (G) 200, and (H) 272 per cent of their controls.

I have already mentioned the characteristic behavior of the strychninized rats when approaching the turns in the maze (p. 149). Those rats which showed other effects of the drug, tremor, etc., usually slowed down and approached the entrance from one alley to the next cautiously, turning their heads from side to side and smelling the edges of the opening before going through. This behavior, which did not persist long after the maze-habit became automatized, was never apparent in the caffeinized rats or in the controls. With its disappearance the rate of running increased also to equal or exceed that of the controls. This is shown by the average speed of the rats during the tests for efficiency (table 11).

The caffeinized rats not intrequently seemed to be in a high state of excitement during training. Greater care was necessary in confining them in the food compartment of the maze than for the other groups, as a slight noise or jarring of the maze would bring them rushing from the food to hide in one of the blind alleys of the maze. Once they had begun to acquire the habit their behavior differed less from the strychninized rats and from the controls, but instead of approaching the turns of the maze cautiously, they frequently dashed ahead at a speed which carried them almost past the openings before they could turn. This behavior also became less noticeable as the habit became 
fixed but never completely disappeared. The fact, brought out in table 11, that with long training their rate of running under the influence of the caffeine became less than without the drug is due to the fact that more errors were made under the former conditions and more time was lost in turning and other activities which did not increase the distance traversed.

THE EFFECT OF THE DRUGS UPON EFFICIENCY OF PERFORMANCE OF A MOTOR HABIT

For further information which might be of service in interpreting the data on learning a series of tests upon the effect of

TABLE 11

Data on the effects of strychnine and caffeine on efficiency in the performance of $a$ motor habit. The averages (except those marked first ten trials) are each based upon 180 trials

\begin{tabular}{|c|c|c|c|c|c|c|}
\hline arover & RECHVING & $\begin{array}{l}\text { AVERAGE } \\
\text { DERTANGE } \\
\text { PER TRIAL }\end{array}$ & $\begin{array}{c}\text { AVERAGE } \\
\text { EXXESS } \\
\text { DISTANCE } \\
\text { PRR TRIAL }\end{array}$ & $\begin{array}{c}\text { AVERAGE } \\
\text { TMME PER } \\
\text { TRIAL }\end{array}$ & $\begin{array}{c}\text { TOTAS } \\
\text { NUMBER of } \\
\text { FRBRORB }\end{array}$ & 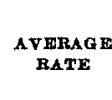 \\
\hline \multirow{4}{*}{1} & & meters & meters & seconds & & m.p.s. \\
\hline & (Water $010 \mathrm{cc}$. & 524 & 089 & 10.5 & 85 & 049 \\
\hline & Strychnine $010 \mathrm{mgm}$. & 467 & 0.32 & 83 & 35 & 0.56 \\
\hline & First ten trials & 5.16 & 0.81 & 10.6 & $33(99)$ & 048 \\
\hline \multirow{3}{*}{2} & Water $010 \mathrm{cc}$. & 530 & 095 & 10.9 & 76 & 0.48 \\
\hline & Strychnine $0.10 \mathrm{mgm}$. & 504 & 069 & 97 & 68 & 0.52 \\
\hline & First ten trials & 5.09 & 0.74 & 11.0 & $25(75)$ & 046 \\
\hline \multirow{3}{*}{$\mathbf{3}$} & Water $010 \mathrm{cc}$. & 506 & 0.71 & 9.4 & 71 & $04 \pi$ \\
\hline & Caffeine $050 \mathrm{mgm}$. & 527 & 0.92 & 12.8 & 90 & 041 \\
\hline & First ten trials & 539 & 1.04 & 10.8 & $38(114)$ & 0.49 \\
\hline
\end{tabular}

the drugs upon the established maze-habit was carried out. Eighteen rats which had learned and relearned the maze were divided into three groups and given five trials per day in the maze for fourteen successive days. On the first two days all were given subcutaneous injections of 0.10 cc. of water ten minutes before they were started in the maze. A comparison of their efficiency with and without the drugs was then made in the following way. For two consecutive days the drug was 
given by subcutaneous injection; on the following two days only water was given; and again the drug on the next two days. To control the effects of practice during the test three rats in each group received the drug on the first two test days while the remaining three received water on these days and the alternations were continued regularly with each three. The three groups were given alternately (1) water, $0.10 \mathrm{cc}$. and strychnine sulphate, $0.10 \mathrm{mgm}$.; (2) water, $0.10 \mathrm{cc}$. and strychnine sulphate, $0.05 \mathrm{mgm}$.; (3) water, 0.10 cc., and caffeine, $0.50 \mathrm{mgm}$.

The data obtained in the experiment are summarized in table 11. In the table the averages of the first ten trials are based upon sixty trials, or ten for each rat. The remaining averages are based upon thirty trials for each rat or one hundred and eighty trials altogether. The significant figures for determining relative efficiency with and without the drugs are the rate of running and the number of errors. The differences in rate are not great: for group 1, the rate of running, under the influence of the drug is 114 per cent; for group 2, 108 per cent; and for group 3, 91 per cent of the water control. These differences are in inverse proportion to the number of errors made and are probably due to the time lost in stopping and turning when errors were made.

The superiority of the animals under strychnine as measured either by the excess distance traversed or by the counted number of errors is quite marked. Under strychnine group 1 made 59 per cent fewer errors and traversed 64 per cent less distance than when without strychnine. Under the same conditons group 2 made 11 per cent fewer errors and covered 28 per cent less distance.

Under caffeine the rats of group 3 made 26 per cent more errors and traversed a distance 29 per cent greater than without the drug.

All the rats, with one exception, in groups 1 and 3 , in which the greatest effects of the drugs are evident, were affected in the same way by the drugs. The individual averages of the animals in these groups are given in table 12 . In group 1 every one of the animals made fewer errors while under the 
influence of strychnine than while normal. In group 3 only one of the rats (no. 4) made fewer errors when under the influence of caffeine than when normal and this rat totaled so many more errors than any of the others that his record may perhaps be regarded as abnormal. This result agrees with the data on learning. The animals which learned most rapidly, those under the influence of strychnine, also were most accurate in carrying out the learned activity. Those which required

TABLE 12

Individual records of efficiency of performance in animals receiving doses of strychnine sulphate or cafferne alternately with water

\begin{tabular}{|c|c|c|c|c|}
\hline \multirow{2}{*}{$\begin{array}{c}\text { LABOFATORY } \\
\text { NOMEER OF ANIMAL }\end{array}$} & \multicolumn{2}{|c|}{$\begin{array}{l}\text { TOTAL EXCERS DIBTANCE } \\
\text { IN } 30 \text { TRIALS }\end{array}$} & \multicolumn{2}{|c|}{$\begin{array}{l}\text { TOTAL NUMBER OF ERRORG } \\
\text { IN } 30 \text { TRIALS }\end{array}$} \\
\hline & Water & Strychnine & Water & Strychmne \\
\hline Group 1 & meters & meters & & \\
\hline 14 & 35.5 & 20.7 & 16 & 9 \\
\hline 13 & 63 & 25 & 4 & 3 \\
\hline 16 & 215 & 74 & 14 & 6 \\
\hline 17 & 400 & 100 & 16 & 4 \\
\hline 27 & 17 & 00 & 3 & 0 \\
\hline 28 & 577 & 179 & 32 & 13 \\
\hline Group 8 & & Caffeine & & Caffeine \\
\hline 4 & 67.1 & 572 & 36 & 32 \\
\hline 11 & 8.3 & 144 & 3 & 9 \\
\hline 29 & 9.3 & 201 & 8 & 10 \\
\hline 21 & 18.6 & 264 & 9 & 15 \\
\hline 23 & 3.9 & 114 & 5 & 7 \\
\hline 7 & 21.0 & 365 & 10 & 17 \\
\hline
\end{tabular}

much practice for perfect learning were inaccurate even after having once acquired the required standard of proficiency. It seems that the same factors that resulted in increased or diminished accuracy in performance of the perfected habit were influential also in shortening or prolonging the learning process.

\section{DISCUSSION}

We may summarize the better established results of this work as follows: Strychnine sulphate, when administered in doses large enough to produce obvious changes in tonus, effects 
a saving in the amount of practice necessary for learning. Caffeine in large doses markedly increases the amount of practice consumed in learning and the retardation of the rate of learning seems proportional to the amount of the drug administered.

During training the animals under the influence of strychnine move more slowly, and those under caffeine more rapidly than normal animals. Associated with these effects are a seeming caution in approaching the turns of the maze appearing in the strychninized animals and an exaggerated carelessness in those under caffeine. These effects largely disappear when the habits have become automatized. After the habit has been perfected strychnine increases and caffeine diminishes the accuracy of the animals' performance.

The results are complex and seemingly at variance with the similarity of action accredited to the drugs by pharmacologists, and, in view of our elementary knowledge of their effects upon various sense organs and upon the autonomic nervous system it

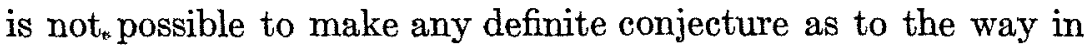
which the drugs bring about their effects upon the learning process.

The most confusing point is the direct opposition of the effects of caffeine and strychnine. Until further data is accumulated upon the physiological action of these drugs it will not be possible to apply the present data to the question of the relation of inhibitory or excitatory nervous activity to learning. A significant suggestion concerning the difference of action of the drugs is given by Sajous ('12). He asserts that the first effects observed after the administration of both drugs result from the stimulation of suprarenal activity: Caffeine is more effective than strychnine in producing this result and its effects are almost wholly confined to this action: Strychnine, however, in large doses soon attacks the spinal centers and its more pronounced effects are due to its action on the central nervous system. I have not been able to find the original data upon which these statements are based and they are not in accord with the more generally accepted accounts of the action of the drugs, although there seems to be no conclusive evidence against 
them. If correct, they go far toward clearing up the problem. The hyper-emotionalism of the caffeinized animals suggests an increased output of adrenalin in agreement with Sajous' conception. It is possible, then that the retarding effects of caffeine on learning are due to endocrine activity, which, in the case of strychnine is obscured by the action of the drug upon the central nervous system.

Since only the larger dose of strychnine affects learning and then only when other symptoms indicate its attack upon the central nervous system it seems probable that its acceleration of learning is correlated in some way with the reduction of synaptic resistances and the increased ease of spread of nerve impulses. This condition should result in a greater diversity of activity, a readier change from one type of action to another, than is possible in a normal nervous system, and might therefore militate against the appearance of stereotyped errors. As this is the sort of error appearing in the later stages of practice it seems possible that the acceleration of learning by strychnine may be effected in this way.

\section{SUMMARY}

Albino rats were trained in the circular maze after subcutaneous injection of strychnine sulphate and of caffeine. Others were trained after similar manipulations but without the drugs, as controls. Analysis of the data obtained gives the following results:

1. Small doses of strychnine sulphate are without effect upon the rate of habit-formation.

2. Large doses of strychnine sulphate, sufficient to produce tremor and incoördination of movement, accelerate learning.

3. Caffeine, in doses of $0.5 \mathrm{mgm}$. or more, retards learning in direct proportion to the size of the dose.

4. Strychnine sulphate in large doses increases the accuracy of performance of a perfected habit.

5. Large doses of caffeine result in increased activity and reduced accuracy of performance. 


\section{REFERENCES}

Amantea, G. Sur les rapports entre les centres corticaux de la circonvolution sigmoide et la sensibilité cutanée chez le chien. Arch. ital, de biol., 1915, lxiii, 143-148.

ANGell, J. R. Psychology, 4th. edition, p. 70, 1909. New York. Holt.

Forbes, A. ANd Gregg, A. Electrical studies in mammalian reflexes. II. The correlation between strength of stimuli and the direct and reflex nerve response. Amer. Jour. Physiol., 1915, xxxix, 172-235.

Goldscheiner, A., dxd Flatad, E. Normale und pathologische Anatomie der Nervenzellen auf Grund der neueren Forschungen. 1898, Berlin.

Hubbert, H. B. The effect of age on habit formation in the albino rat. Behav. Monog., 1915, ii, (No. 11), pp. $\mathrm{v}+55$.

Ladd, G. T., AND WoodWorth, R. S. Elements of Physiological Psychology, p. 551. New York, 1911. Scribner.

LAsHLEY, K. S. The criterion of learning in experiments with the maze. Jour. Animal Behav., 1917, vii, 66-70.

Mexer, Max. The Fupdamental Laws of Human Behavior. Boston, 1911. Badger.

Pawlow. Cited from Babkin, B. P. Die äussere Sekretion der Verdauungsdrüsen. Berlin, 1914. Springer.

SAJous, C. E. DE M. The Internal Secretions and the Principles of Medicine. Philadelphia, 1912, F. A. Davis Co.

Watson J. B. a. Behavior: An Introduction to Comparative Psychology. New York, 1914. Holt.

Watson, J. B. b. A circular maze with camera lucida attachment. Jour. Animal Behav., 1914, iv, 56-59. 